\title{
Assessing Impact of an REU program on Students' Intellectual Growth and Interest in Graduate School in Cybermanufacturing
}

\author{
Mr. Pavan Kumar Moturu, Texas A\&M University \\ Dr. Bimal P. Nepal, Texas A\&M University
}

Dr. Bimal Nepal is a Professor and Associate Director of Industrial Distribution Program at Texas A\&M University. His research interests include integration of supply chain management with new product development decisions, distributor service portfolio optimization, pricing optimization, supply chain risk analysis, lean and six sigma, large scale optimization, and engineering education. He has authored over 100 refereed articles in leading journals and peer reviewed conference proceedings in these areas. He has B.S. in ME, and both M.S. and Ph.D. in IE. He is a member of ASEE, INFORMS, ASEM, and a senior member of IISE.

\section{Prof. Prabhakar Reddy Pagilla, Texas A\&M University}

Prabhakar Pagilla is the James J. Cain Professor in the Department of Mechanical Engineering at Texas A\&M University. He received his $\mathrm{PhD}$ in Mechanical Engineering from the University of California, Berkeley in 1996. His formal background and expertise are in the general areas of dynamic systems and control with applications in manufacturing and robotics. His research interests lie in modeling and control of roll-to-roll manufacturing systems; control of large-scale complex systems; robotics/mechatronics; and adaptive and robust control of nonlinear dynamic systems.

\section{Prof. Satish Bukkapatnam, Texas A\&M University}

Satish T. S. Bukkapatnam received his Ph.D. and M.S. degrees in industrial and manufacturing engineering from the Pennsylvania State University. He currently serves as Rockwell International Professor with the Department of Industrial and Systems Engineering department at Texas A\&M University, College Station, TX, USA. He is also the Director of Texas A\&M Engineering Experimentation Station (TEES) Institute for Manufacturing Systems. His research in smart manufacturing addresses the harnessing of high-resolution nonlinear dynamic information, especially from wireless MEMS sensors, to improve the monitoring and prognostics, mainly of ultraprecision and nanomanufacturing processes and machines, and wearable sensors for cardiorespiratory processes. His research has led to over 160 peer-reviewed publications (100 published/ accepted in journals and 68 in conference proceedings); five pending patents; $\$ 6$ million in grants as PI/Co-PI from the National Science Foundation, the U.S. Department of Defense, and the private sector; and 14 best-paper/poster recognitions. He is a fellow of the Institute for Industrial and Systems Engineers (IISE), and the Society of Manufacturing Engineers (SME), and his work has been recognized with Oklahoma State University regents distinguished research, Halliburton outstanding college of engineering faculty, and Fulbright-Tocqueville distinguished chair awards. 


\title{
Assessing Impact of an REU program on Student's Intellectual Growth and Interest in Graduate School in Cybermanufacturing
}

\author{
Pavan K. Moturu, Bimal Nepal, Prabhakar Pagilla, Satish Bukkapatnam \\ Texas A\&M University, College Station, TX.
}

\begin{abstract}
Advancements in information technology and computational intelligence have transformed the manufacturing landscape, allowing firms to produce highly complex and customized product in a relatively short amount of time. However, our research shows that the lack of a skilled workforce remains a challenge in the manufacturing industry. To that end, providing research experience to undergraduates has been widely reported as a very effective approach to attract students to industry or graduate education in engineering and other STEM-based majors. This paper presents assessment results of two cohorts of Cybermanufacturing REU at a major university. Students were recruited from across the United States majoring in multiple engineering fields, such as industrial engineering, mechanical engineering, chemical engineering, mechatronics, manufacturing, and computer science. Several of the participants were rising sophomores or juniors who did not have any industry internship or prior research experience. In total 20 students (ten per year) participated in the program and worked on individual project topics under the guidance of faculty and graduate student mentors. Unlike a typical REU program, the Cybermanufacturing REU involved a few unique activities, such as a 48-hour intense design and prototype build experience (also known as Aggies Invent), industry seminars, and industry visits.

Overall, the REU students demonstrated significant gains in all of the twelve research-related competencies that were assessed as a part of formative and summative evaluation process. While almost all of them wanted to pursue a career in advanced manufacturing, including Cybermanufacturing, the majority of the participants preferred industry over graduate school. The paper provides an in-depth discussion on the findings of the REU program evaluation and its impact on undergraduate students with respect to their future plans and career choice. The analysis is also done by gender, ethnicity, academic level (sophomore, junior, senior), and type of home institution (e.g., large research universities, rural and small schools) to explore if there was any significant difference in mean research competency scores based on these attributes.
\end{abstract}

\section{Introduction}

Today's manufacturing operations are more complex and globally scalable compared to those in the last century (Lee et al., 2016). This complexity in manufacturing operations is due to a shift in manufacturing from craftsmanship model in the $19^{\text {th }}$ century to, mass production in the $20^{\text {th }}$ century, and now to fully automated factory model in the $21^{\text {st }}$ century. The automation and increasing customization in manufacturing in the last decade have necessitated a change in manufacturing systems in order to adapt to new challenges without disrupting the supply chains (Srinivasa and Bukkapatnam, 2014). Due to advancements in the web-based cyber physical systems, it is now possible for factories to use cyber workspace to achieve efficient and effective operations that are complex and globally scalable (Wang, 2014). This application of cyber physical systems to conventional industries can be defined as Cybermanufacturing (Lee et al., 2015; Wang and Wang, 2018; Song and Moon, 2017).

Cybermanufacturing is a system which utilizes data from individual units of interconnected systems to predict and prescribe operations to achieve a robust performance. Cybermanufacturing 
addresses the following transformations in manufacturing: 1) from machine based to evidencebased decision making 2) from solving visible problems to avoiding invisible problems; and 3) from control-oriented machine learning to data rich deep learning (Lee et al., 2016). All of these transformations help the factories to produce highly customized products with short product life cycles without straining their operational efficiency and scalability. In other words, this new paradigm transforms manufacturing into a "cloud-based service" (Srinivasa and Bukkapatnam, 2014).

In order to sustain the new development in manufacturing processes and technologies, it is critically important that there is skilled workforce to support the industry. Prior research has pointed to a talent gap in manufacturing industry (Javdekar et al., 2016). To that end, multiple initiatives are taking place on different levels. For example, at the industry level, many initiatives are being taken by the companies to bridge this gap, such as upskilling the current workforce through continuing education (Nepal et al., 2019), or partnering with an academic institution in developing appropriate program or curriculum (Nepal et al., 2016; Seemakula et al., 2010). At the university level, besides offering academic degree programs in manufacturing or similar STEM programs, many institutions of higher learning also provide research experiences for undergraduates (REU) to build a stronger and more diverse pipeline for future researchers and industrial workforce (Bonne et al., 2018; Jiang et al., 2019). Lastly, at the government level, investment in programs such as REU, research experience for teachers (RET) and advanced technological program (ATE) funded by the National Science Foundation are intended to narrow this gap in workforce. There are additional agencies such as the U.S. Department of Labor, the Department of Education, and the Department of Energy also have workforce development components in their grant programs.

This paper presents a case study of a NSF-funded Cybermanufacturing REU program at Texas A\&M University in College Station, Texas. The objective of the paper is to evaluate impact of the REU program on multiple student outcomes with respect to their research competencies such as understanding a research process, data gathering, analyzing, and presentation of results. The analysis is also broken down by gender, ethnicity, student type (junior, senior, etc.), and type of their primary institutions (major research school vs. teaching school). The cybermanufacturing REU programs recruits students both from in-state and out of state of Texas. In addition to most commonly held10-week long research program under the guidance of a faculty mentor, the cybermanufacturing REU also engages students in high impact learning and entrepreneurial experience such as "Aggies Invent" program (Aggies Invent, 2020) offered by the College of Engineering at Texas A\&M University.

The remainder of the paper is organized as follows. In section 2, it provides a brief background on the Texas A\&M REU Site in cybermanufacturing. Section 3 discusses recruiting process used to select the REU participants including a summary of the most recent two cohorts. In section 4 , it discusses the sample student projects. In section 5, the paper provides a summary of findings related to impact of REU program on student research outcomes. Lastly, section 6 concludes the paper by summarizing the key findings.

\section{Program Background}

The goal of NSF-funded REU program in Cybermanufacturing at Texas A\&M University is to instill interest in advanced manufacturing research and careers among undergraduate students. The program recruits 10 students each year and provides them with an opportunity to work on an advanced manufacturing research project under the guidance of a faculty and a graduate student 
mentor. The following are the main objectives of this program: a) improve research skills of the students in STEM fields in general, and in the fields of advanced manufacturing in particular; b) enhance student's interest in advanced manufacturing as it relates to graduate education or industry career; c) provide guidance to students on their graduate school selections and applications; and d) provide the participants with engineering innovation and entrepreneurship activities such as designing, prototyping, and communicating ideas to stakeholders . This program duration is 10week long which spans from the last week of May through the first week of August. Like any other REU program funded by the NSF, this is also a paid internship program in which students are provided with a stipend of $\$ 500$ per week including a free residence during the period. In addition to faculty-led research projects, the REU participants participate in safety training, research seminars, industry seminar, Aggies Invent, industry visit, GRE workshops, and graduate school admission application process workshop. Lastly, at the end of the program, students are required to present their research at a summer research symposium organized by the Texas A\&M University's college of engineering which also includes several other undergraduate researchers than just the REU participants.

\section{Student Recruiting}

The goal of the cybermanufacturing REU program was to recruit the majority of students outside of Texas A\&M University including those from out of state of Texas. The program was advertised through multiple professional societies listservs including IISE, ASME, and ASEE. The interested students could submit their applications online through the REU program website (https://cybermanufacturing.tamu.edu/) and also through the NSFREU.org website. In order to broadening the participation, the PI team also reached out to a select number minority serving institutions to advertise the program.

In both cases of the last two recruiting cycles (2018 \& 2019), over 100 applications were received including many from both in and out-of-state institutions. As targeted by the program, the applications received covered a very diverse background with respect to ethnicity, gender, location, academic standing, university of study including a good number of minority-serving institutions. Figure 1 illustrates the classification of the applicants by research interest, ethnicity, gender and location. 


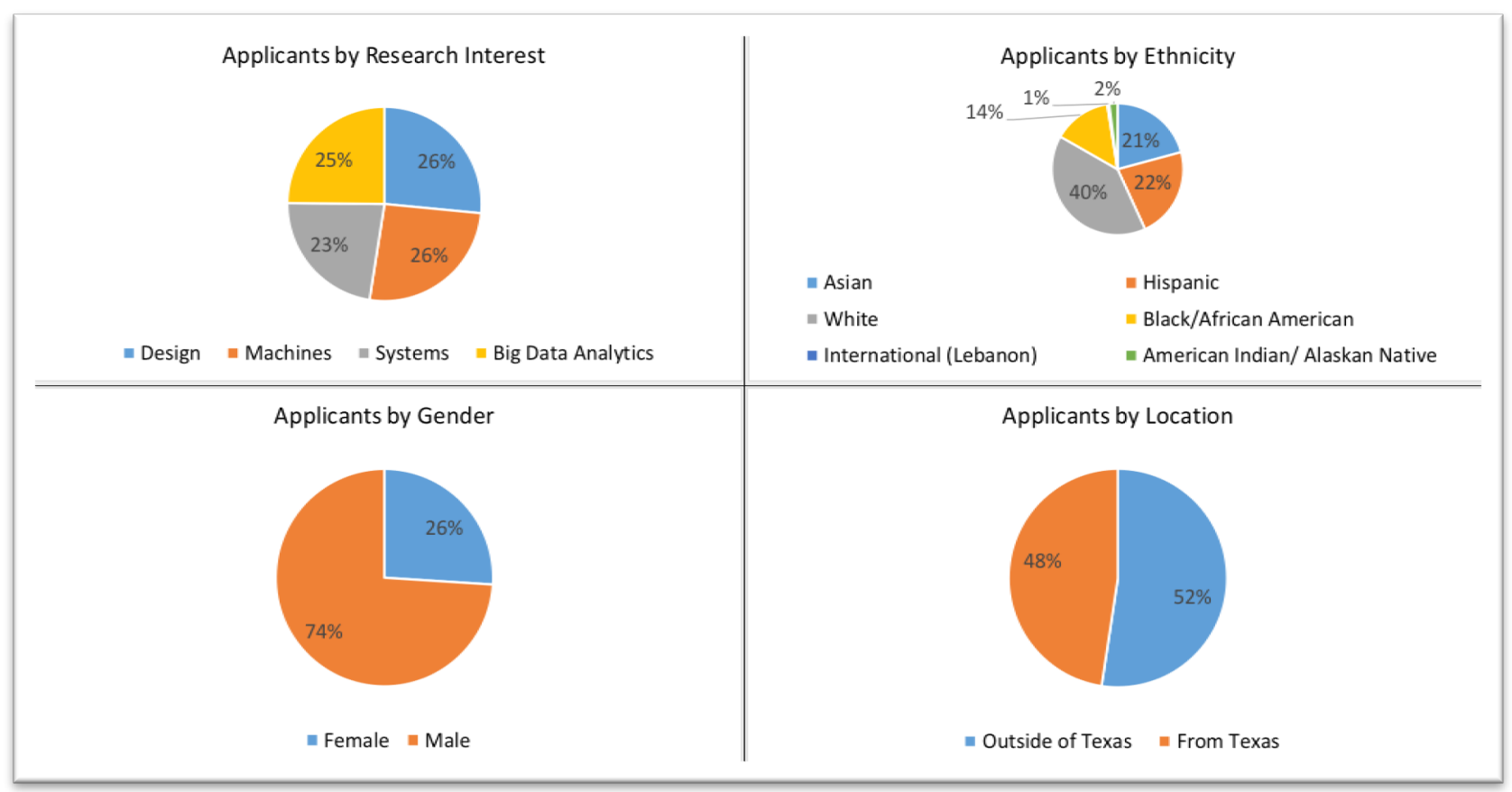

Figure 1: Summary of 2018 \& 2019 Cohorts

As shown in Figure 1, more than half of the applicants were from outside the State of Texas. Although not shown in Figure 1, in overall, we received applications from 39 states. Similarly, over one third of the applicants were from minority population groups, mainly Hispanic and African American. It may be noted that the data in the first quadrant of Fig. 1 does not include the applicants through NSF website since that question was not included in that application form.

\subsection{Students selection process}

Student selection process involved a holistic review of their application package. First, students were shortlisted based on the minimum requirements as outlined in the project document, which included: 1) a major in STEM field; 2) cumulative GPA of 3.0 or more on a 4.0 scale; 3) U.S. citizenship or permanent residency; and 4) at least one semester remaining after the summer program. The PI team then reviewed the shortlisted applicants with respect to few additional factors such as diversity, location, academic standing, prior research experience, programming knowledge, knowledge of engineering principles through their coursework and personal essays. After the review process was completed, the PI team shortlisted 10 students who were then contacted individually to confirm their interest and availability. Upon receiving the availability and time commitment information from the applicants, ten students were offered the position. The program advertisement process began in late fall and the final selection of the participants was completed by early April. Unfortunately, some decisions had to be made in late April or early May because of late cancellation by the students who could not join the program due to family and other circumstances.

\subsection{Summary statistics of the 2018 and 2019 participants}

Figure 2 depicts the REU participants summary (both 2018 and 2019 cohorts combined) broken down by research interest, ethnicity, gender and location. The goal of the program was to recruit at least $50 \%$ women and minority students, and over $80 \%$ from outside of Texas A\&M, with one third from outside of Texas. Figure 2 shows that the program was able to succeed in its diversity goal. Although in the initial shortlist there were over $40 \%$ of students out of state of Texas, because 
of the last-minute drop-out, the out-of-state goal could not be realized in both 2018 and 2019. At the end, with respect to location, there were only $30 \%$ participants who came from outside of Texas and $50 \%$ outside of Texas A\&M University.

On the other hand, in overall the participants represented eight universities and one community college apart from Texas A\&M. Of these eight universities, six of them were from non-Texas schools. Figure 3 presents the participants percentage by university and colleges.

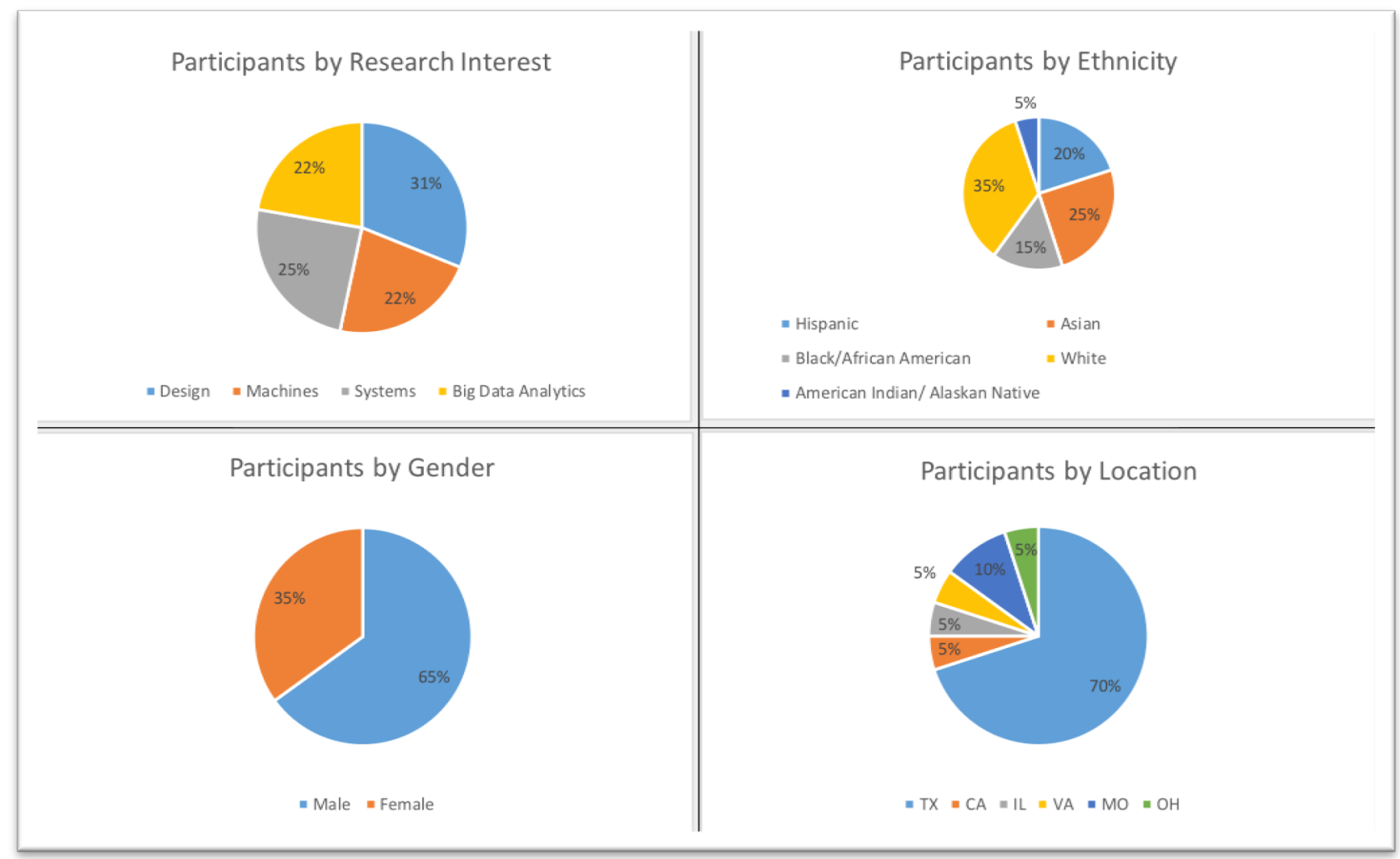

Figure 2: Summary of participants in 208 and 2019 summer programs 


\section{Participants by University}
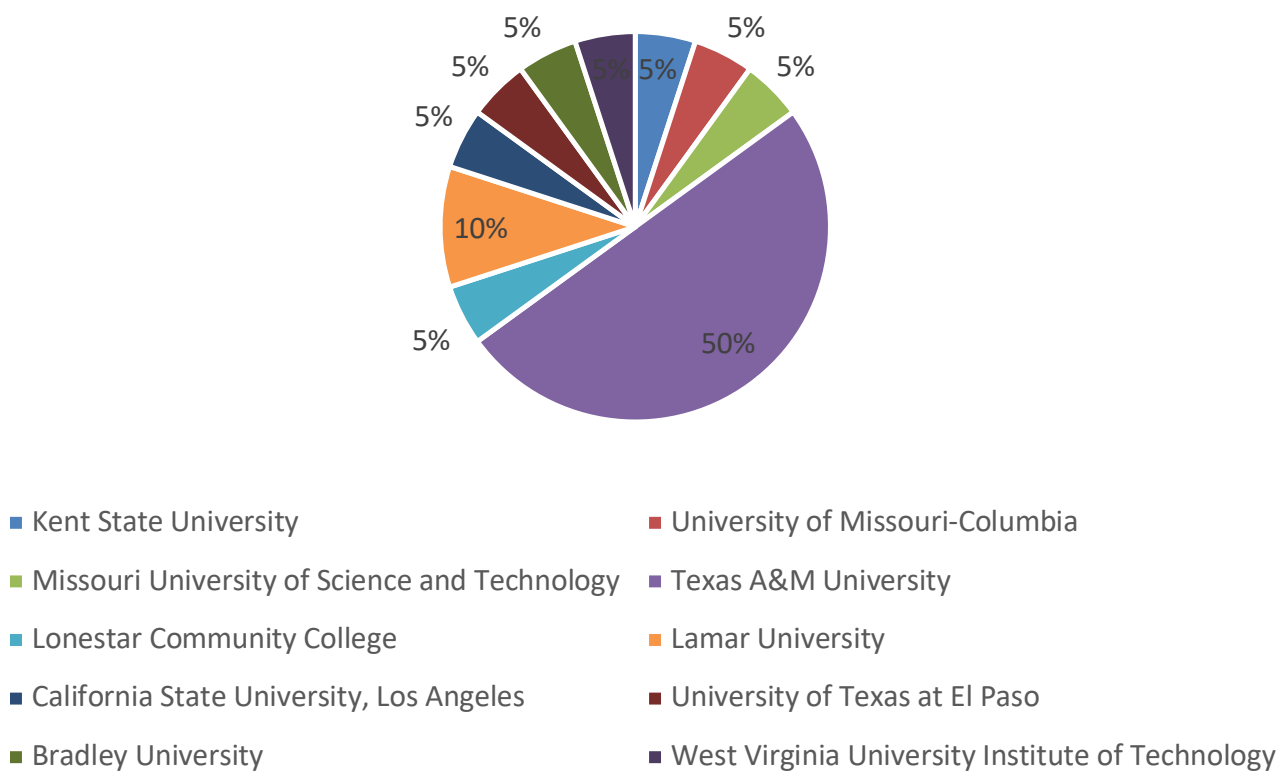

Figure 3: REU Participants broken by their primary institution.

\section{REU Student Projects}

As mentioned earlier, all REU participants were assigned to a faculty mentor with diverse research background to guide them in their projects. Assignment of faculty mentors to students was done by the PI team considering student's strength/interest and mentor's research area. The assignment of research project topic and scope was determined by the respective faculty mentors based on the mutual understanding between the student and his/her mentor. As shown in Figure 4, the research topics covered three broad areas of cybermanufacturing including design \& process planning, prognostic \& process control, and enterprise wide integration and coordination of manufacturing systems.

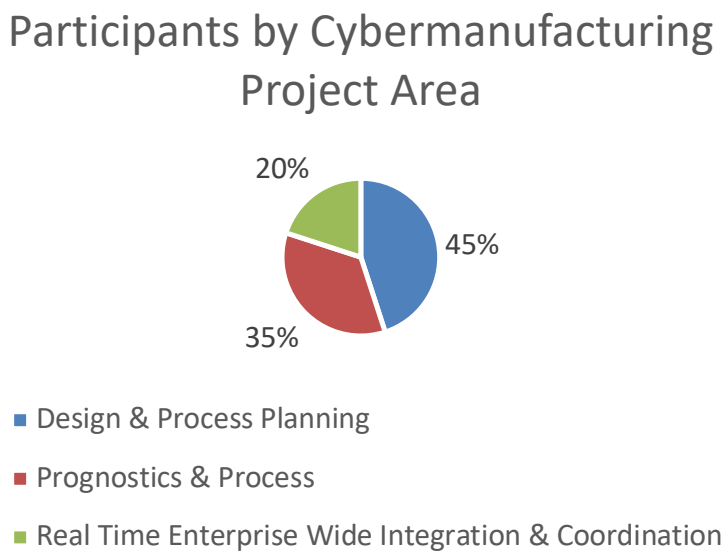

Figure 4: Student distribution in the Cybermanufacturing project areas 
Additionally, following paragraphs provide a brief description of sample projects that REU students worked on:

1. Creating ultra-strong $3 D$ printed parts with multifunctionality using carbon nanotubes (2019) This project was focused on improving the overall strength of the 3D printed parts using Fused Filament Fusion method. The student worked on adding carbon nanotubes and cellular nano crystals to ABS polymers to create multifunctional filaments for printed parts. These parts had improved overall strength along with improved stiffness, electrical, and thermal conductivity.

2. Security issues and challenges in Cybermanufacturing (2019)

This project dealt with the cybersecurity issues and challenges at each stage of manufacturing and creating a risk mitigation framework for these issues. The student completed literature review of various articles related to manufacturing and developed a comprehensive list of security threats. The student also identified best practices in various industries and developed a risk mitigation framework.

\section{Vat photo polymerization $3 D$ printing (2018)}

This project dealt with the nanoscale reinforcement materials in stereo lithography resins to improve the hardness, tensile strength, impact strength, elongation and electrical conductivity of the printed products. The student produced the 3D printed product with reinforcements of nanocomposites and analyzed the quality improvement of the product. The product was tested and analyzed for performance with respect to mechanical properties, electrical properties and biomedical properties.

\section{Adding defects to lightweight elastomers to increase toughness (2019)}

This project was about adding defects to silicon-based elastomers to increase its resistance to fracture. The student conducted various experiments on defect size and density to improve the toughness of the elastomer. Overall, the toughness of elastomer was increased by this process.

5. Self-calibration algorithm for training a displacement sensor based on artificial neural network model (2019)

This project was focused on alleviating the tedious task of calibrating displacement sensors in the laboratory. The student trained an artificial neural network model to collect data from the sensor. The student also developed a regression model to predict the millivolt values which are used to calibrate the sensor without manual intervention.

6. Piezoelectric sensors for high frequency force sensing (2019)

This project was about the frequency constraints on conventional sensors used in CNC machines to measure the forces between tool and material. The student demonstrated the use of piezoelectric sensors for accurate measurement of forces at higher frequency compared to conventional sensors.

7. Synthesis and characterization of magnetic fluids for localized polishing of free form surfaces (2019)

This project was about using magnetic fluids for surface polishing because they can take form of any shape and fit through small areas. The student worked on resynthesizing the magnetic 
fluids i.e. synthesizing the fluids at various concentrations and identifying the ideal mixture. Student has also performed characterization tests like viscosity test, downforce test to verify the fluid mixture.

8. Synthesis of branched zinc phosphide nanowires for mass production (2019)

This project aimed at enhancing the water purifying and photo voltaic properties of zinc phosphide nanowires by increasing the surface area through branching. The student developed a method to form branches at 90 degrees in zinc phosphide nanowires. This method seeds the nanowires with tin nano particles using drop casting, then the nanowires are placed in CVD chamber to react with zinc and phosphorous to form branches.

\section{Optimal magnetorheological fluid for localized polishing of freedom surfaces (2018)}

This project studied magnetorheological fluid that changes properties in the presence of magnetic field. This property is used for polishing of difficult to reach surfaces in the aerospace and biomedical industry. The student optimized the fluid mixture used for polishing to create optimal amount of fluid flow and desired stiffness of the fluid on the polishing surface.

\section{Dynamics modeling and control of a lab scale simulator for autonomous downhole robotic} (2019)

This project focused on automation of state of art directional drilling process in oil and gas industry to allow precision drilling. The student developed a robotic system with advanced closed loop control interface capable of autonomous downhole drilling.

\section{Evaluation of REU program: Pre Vs Post REU experience}

This REU site has been involving an external project evaluator to assess the project objectives and outcomes. A pre-REU and a post-REU survey was developed and utilized to gather the data. The survey questions were designed to assess the competency of students with respect to twelve student research outcomes that included the following: formulate research plan, conduct background research, perform data validation, define scientific arguments, apply theory, prepare and present research poster, formulate hypothesis, develop research questions, analyze experimental results, understand publication process, understand cybermanufacturing projects, and understand project outside research area. The research outcomes related questions were developed on a 1-5 Likert scale where 5 being the best. In addition, there were some open-ended questions related to program logistics, student feedback on other enrichment activities such as Aggies Invent, industry seminar, plant visit, etcetera. The data was conducted from 2018 and 2019 cohorts, that is, a total of 20 participants. According to the survey conducted by an external project evaluator, students had a very positive experience with the REU program in both years. Students found the program activities like plant visit and industry seminars to be very helpful in understanding the application of textbook knowledge in the real world context. Students also acknowledged the mentorship of the faculty to be very helpful in their research work especially in areas like lab work, technical writing and publications. They found the REU program to be very helpful in learning advanced skills like 3D printing, programming and cyber security. In overall, as shown in Figure 5, there was a net positive gain in average student research competencies scores in post REU survey compared those in pre-REU survey. 


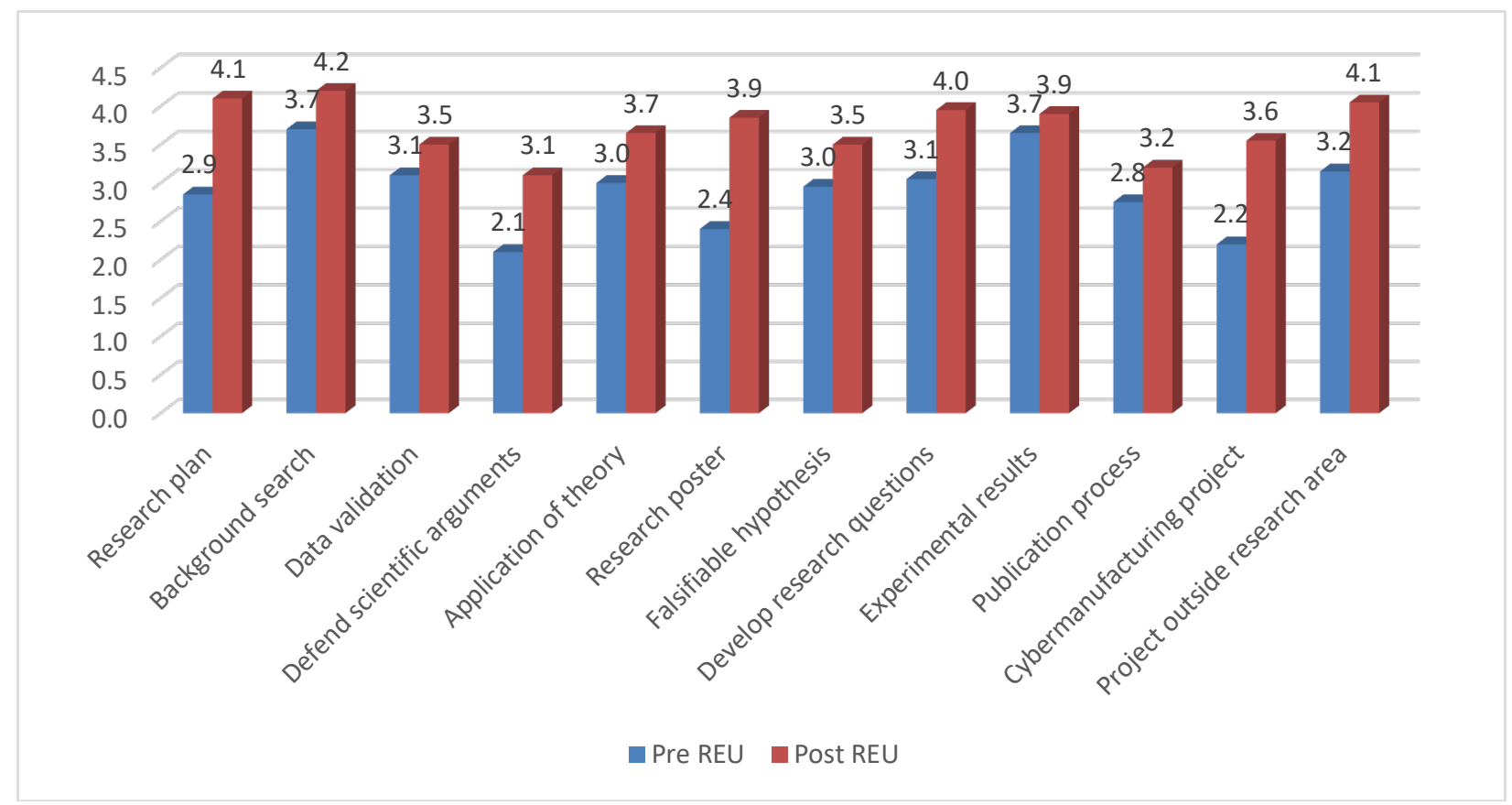

Figure 5: Average competency score before and after the REU experience

Further, this paper also investigated additional research questions to understand if the gain in research competencies varied by the different student populations groups. To that end, the average pre and post survey scored were compared for the different student groups based on gender, ethnic diversity (URM and Non-URM), type of home institution (research university vs. teaching university where they may not have had enough exposure to research activities). In our survey, the gain in student competency were observed across the board as shown in Figures A.1-A.8 in the appendix. However, it may be noted that the level of increase in research competency did vary between the groups. For example, in the increase in competency were observed higher in NonURM group compared that in URM group. Similar observations were made in students from large Doctoral level universities compared to that in those who came from the Master level universities. On the other hand, interestingly, we found that the gains in in competency scores were higher in sophomore than those in juniors and seniors. One explanation could be juniors and seniors would have had internship or some prior research experience coming in therefore the magnitude of increase was not as high compared to the same for the sophomore who usually would not have had any such prior experiences.

\subsection{Impact of REU program on student's interest in graduate education}

In the survey, students were also asked their future plans upon completion of current undergraduate degree. Figure 6 shows percentage of students who were planning to pursue a graduate degree in Cybermanufacturing or other related STEM fields before and after the REU program. From the graph, it can be observed that there was gain in preparedness of students to pursue a graduate education following the REU programs. It may be noted that not all students were planning to start graduate school right after the graduation from their B.S. degrees. 


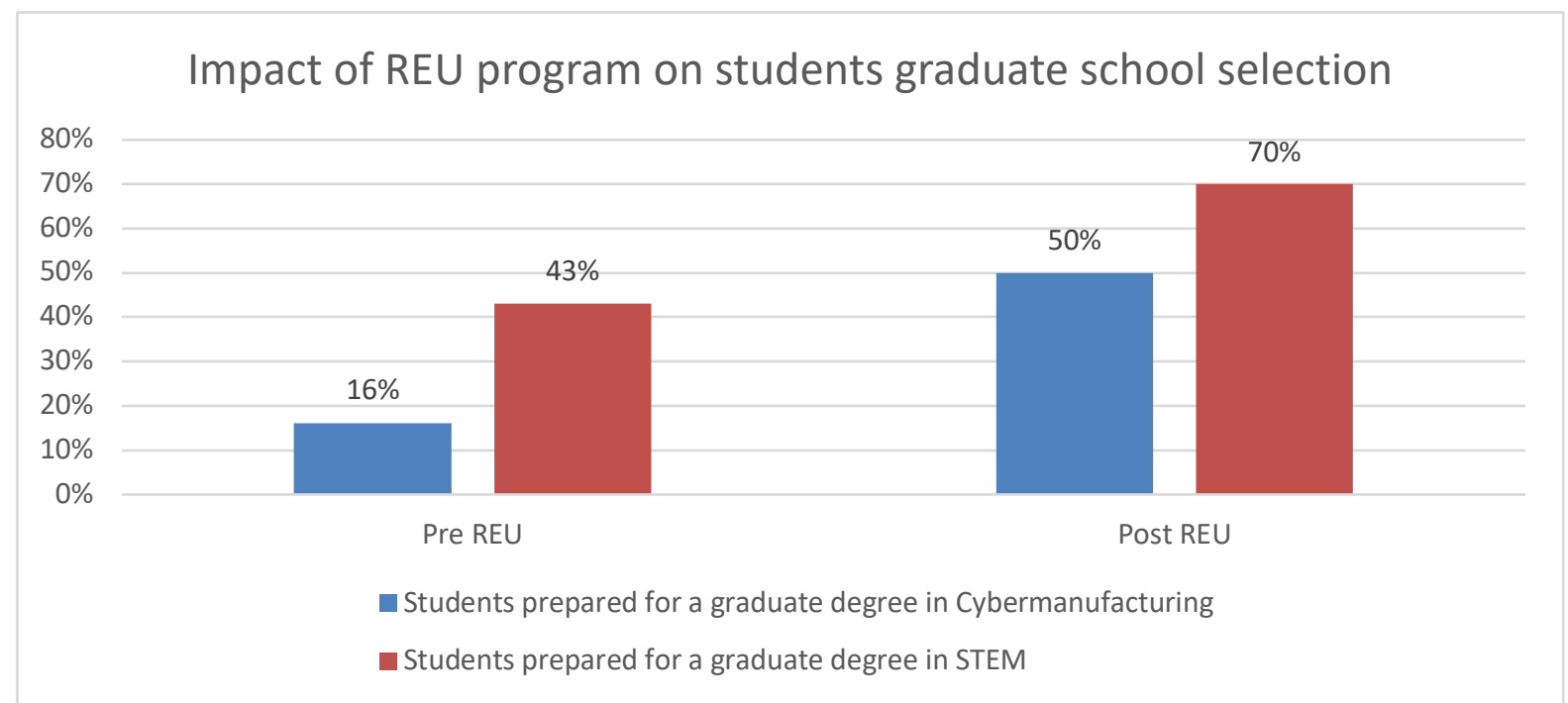

Figure 6: Percentage of students prepared for a degree in Cybermanufacturing and STEM

\subsection{Impact of REU program on student's career choice}

Majority of students at least in 2018 cohort expressed their interest in joining industry career upon completion of their current B.S. degrees in engineering. As shown in Figure 7, the REU seems to have a net positive effect in their career choice in industry whether it is directly in cybermanufacturing or any other related STEM fields. Overall, the survey showed that $90 \%$ of the students felt that they were prepared to pursue a career in STEM field as a result of the REU program.

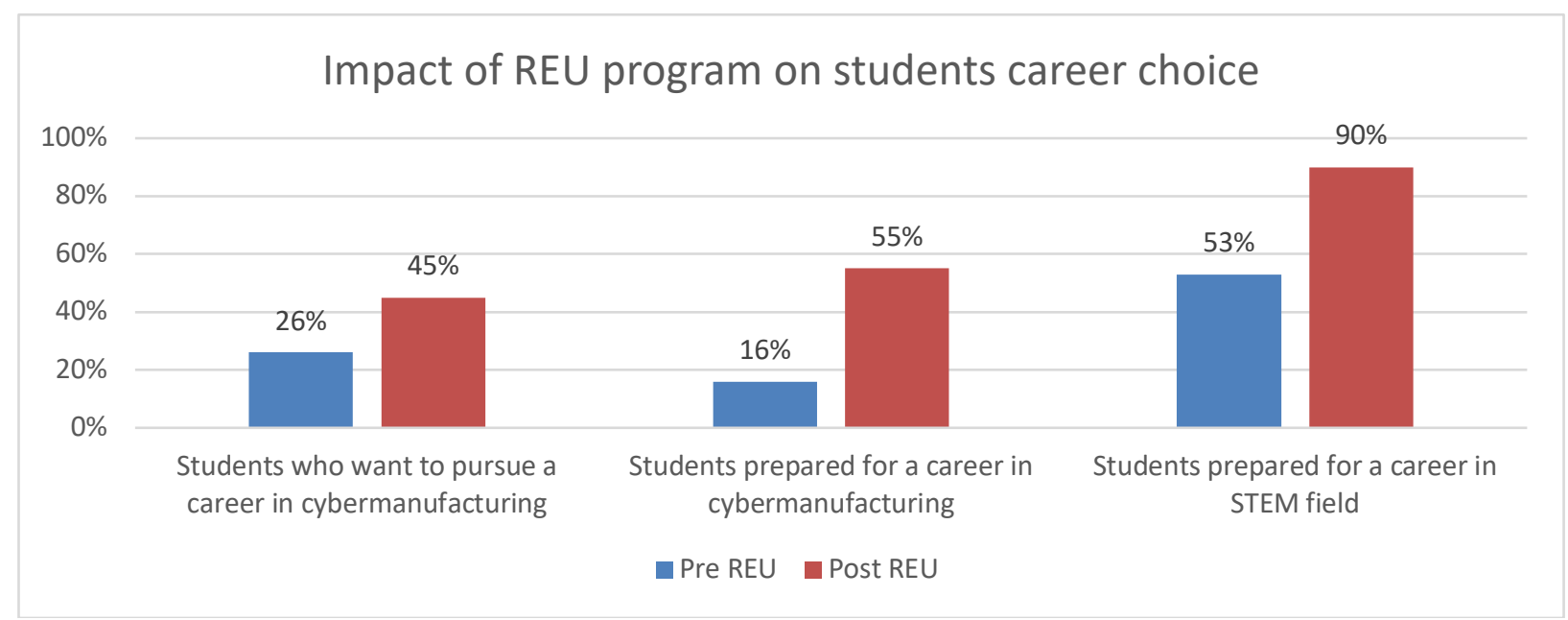

Figure 7: Percentage of students prepared for an industry career in cybermanufacturing

\section{Conclusions}

Manufacturing industry has evolved from craftmanship and mass production models in the past centuries to current highly customized and advanced additive and bio-manufacturing technologies in the $21^{\text {st }}$ century. This transformation is demanding an integration of hardware and software at all levels of the manufacturing operations. Growing applications of advanced technologies like cloud computing, 3D printing, machine learning, and big data are making this transformation feasible at a faster pace than ever before. Even though advanced technologies are enabling this transformation, the employment data from the government shows that the US manufacturing in 
general is facing a shortage of skilled workforce. Furthermore, prior researchers have also reported that Americans and European youths have negative perception about manufacturing jobs as being dirty and low paid among. To that end, there is a sustained effort from the US government to narrow this gap by making investments in such programs as research experience for undergraduates, research experience for teachers, and advanced technological education programs.

This paper presented the impact of one such NSF-funded REU program on student's career and graduate school decisions related to Cybermanufacturing. The REU program recruited 20 students, 10 each in 2018 and 2019 cohorts, who participated in a 10 week long summer research program at Texas A\&M University. These students worked on individual research projects under the guidance of faculty and graduate student mentors from multiple engineering departments at Texas A\&M University. The students also participated in several enrichment activities like the industry visits, industry seminars, Aggies Invent program, and GRE workshops other than the faculty led research projects. A structured survey instrument was employed to assess the impact of REU program on research competency of students with respect to 12 student outcomes. The survey results showed that there were net positive gains in average research competency scores with respect to all twelve outcomes. These observations were seen across the student populations groups regardless of gender, diversity, student academic standing, and the type of their home institutions. Lastly, the survey results have revealed that the students felt better prepared for both graduate school and industry career following the REU experience.

Acknowledgement: This research was supported by a REU Site grant from the National Science Foundation (\# EEC 1757882). Any opinions, findings, conclusions, or recommendations presented are those of the authors and do not necessarily reflect the views of the National Science Foundation.

\section{References}

1. Aggies Invent : Solving Problems in 48 Hours, Engineering Entrepreneurship program, College of Engineering, Texas A\&M University, https://engineering.tamu.edu/studentlife/aggies-invent/index.html (accessed, May1, 2020).

2. Nepal, B., Pagilla, P. R., Srinivasa, A., Bukkapatnam, S., Moturu, P., 2019, "Preparing Next Generation of Manufacturing Leaders: A case of REU site in Cybermanufacturing", 2019 ASEE Annual Conference and Exposition, Tampa, FL.

3. Lee, J., Bagheri, B., Kao, H.A., 2015, “A cyber-physical architecture for Industry 4.0 manufacturing systems", Manufacturing Letters, Vol. 3, pp. 18-23.

4. Lee, J., Bagheri, B., Kao, H.A., 2016, "Introduction to Cybermanufacturing", Manufacturing Letters, Vol. 8, pp. 11-16.

5. Nepal, B., Johnson, M.D., Henri, M., Perez, N., Burillo, M., Sanchez, R., 2016,” Adaptive learning environment for high value manufacturing (HVM) geared towards energy industry", Proceedings of the ASEE National Conference, New Orleans, LA.

6. Srinivasa, A., Bukkapatnam, S., "Cyber manufacturing: A Primer", Texas A\&M Engineering Experimentation Station, Institute of Manufacturing Systems, 2014. http://tees.tamu.edu/media/197462/cyber-manufacturing-primer.pdf

7. Song, Z., Moon, Y., 2017, “Assessing sustainability benefits of Cybermanufacturing systems", International Journal of Advanced Manufacturing Technology, Vol. 90, pp. 1365-1382. 
8. Wang, L., Wang, X.V., 2018, "Cloud-Based Monitoring, Planning, and Control in CPS", Cloud-Based Cyber-Physical Systems in Manufacturing, Springer, pp 82-82.

9. Javdekar, C., Watson, E., Kapilow, V., Bograd, M., Boyer, P., Zeid, I., Duggan, C., 2016, "Closing the Advanced Manufacturing Talent Gap", Procedia Manufacturing, Vol.5, pp. 1197-1207.

10. Nepal, B., Johnson, M., 2019, "Bridging the Workforce Skills Gap in High Value Manufacturing through Continuing Education”, 2019 ASEE Annual Conference and Exposition, Tampa, FL.

11. Wang, L., 2014, "Cyber Manufacturing: Research and Applications", Proceedings of the 10th International Symposium on Tools and Methods of Competitive Engineering, Vol. 1, pp. 39-48.

12. Jiang, Z., Caicedo, J., Petrulis, J., 2019, "Development and Implementation of an NSF REU Site with Integrated Academia-Industry Research Experience", Proceedings of the ASEE Annual Conference \& Exposition, pp. 3751-3758.

13. Bennie, B., Eager, E.A., Peirce, J., Sandland, G.J., 2018, "Using a Summer REU to Help Develop the Next Generation of Mathematical Ecologists" Society of Mathematical Biology, pp. 926-944.

14. Economy, D.R., Martin, J.P., Kennedy, M.S., 2013, "Factors Influencing Participants Selection of Individual REU Sites", IEEE Frontiers in Education Conference (FIE), Oklahoma City, OK, pp. 1257-1259.

15. Seemakula, M., Liao, G., Ellis, D., 2010, "Closing the Competency Gap in Manufacturing Processes As It Applies To New Engineering Graduates”, ASEE, 2010.

\section{Appendix: Student outcomes assessment scores comparison by participants type}

This section shows the bar charts of Pre vs. Post scores for 12 student research outcomes assessed in this research.

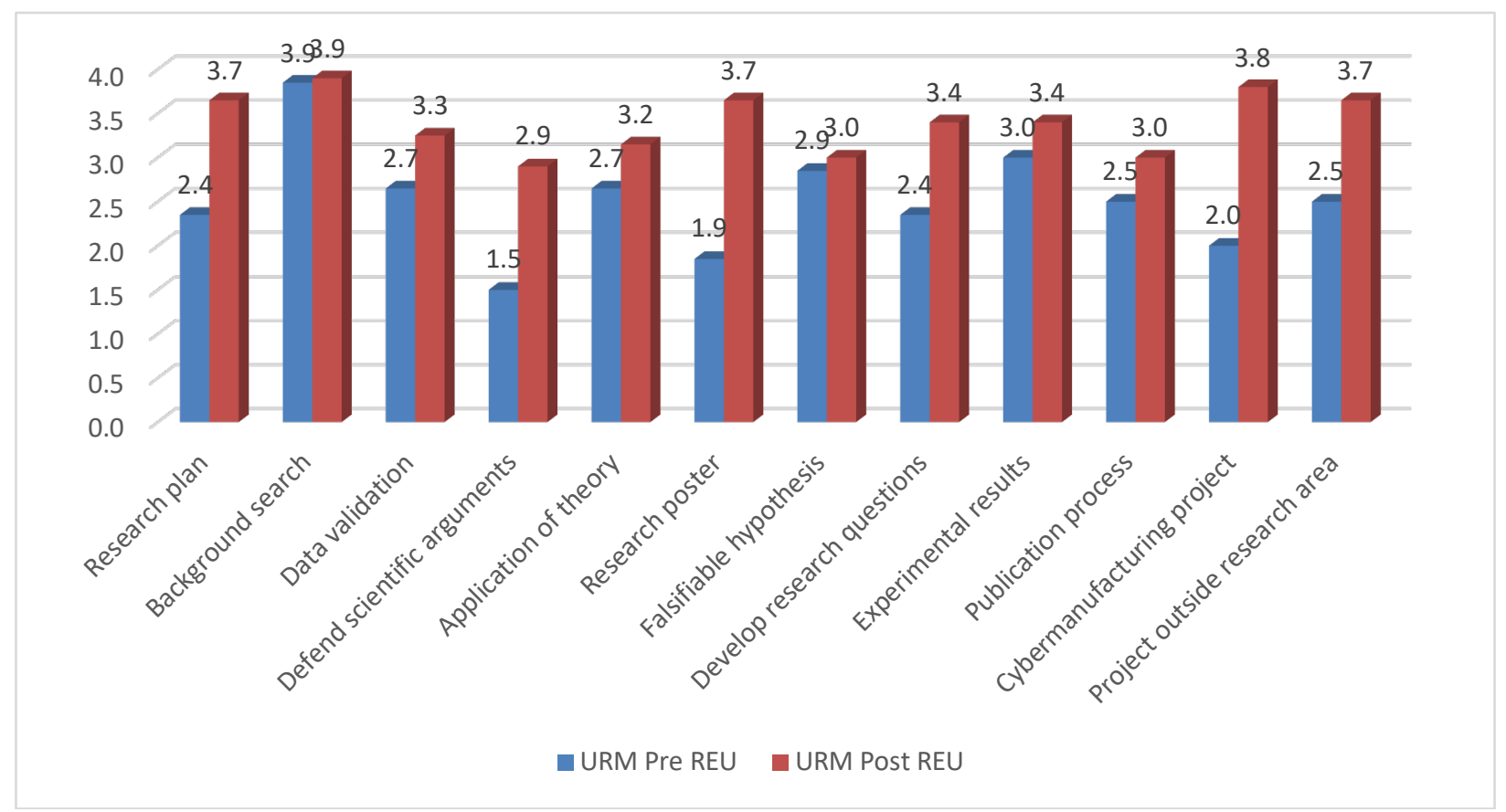

Figure A.1: Average competency score for URM student groups 


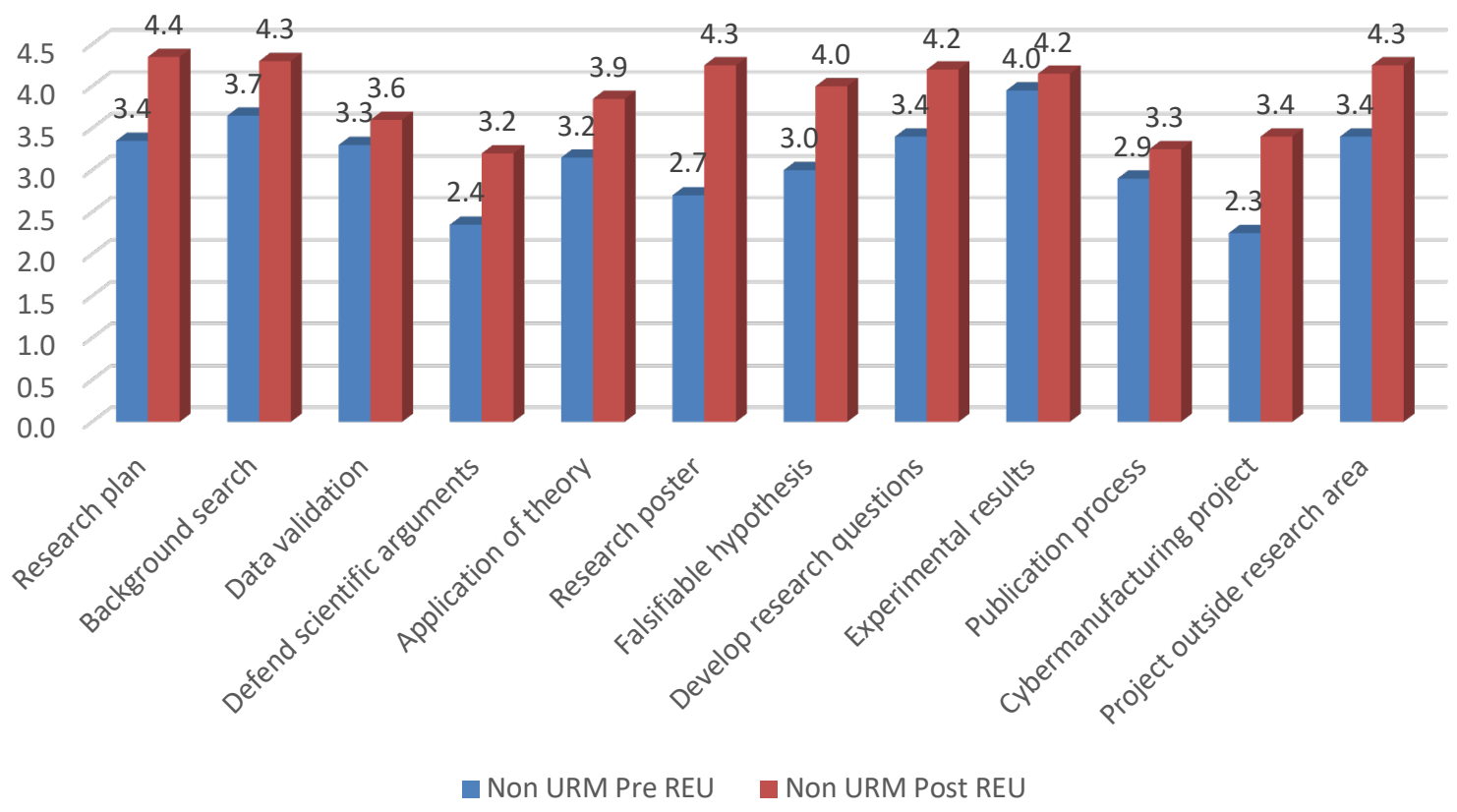

Figure A.2: Average competency score for Non-URM student groups

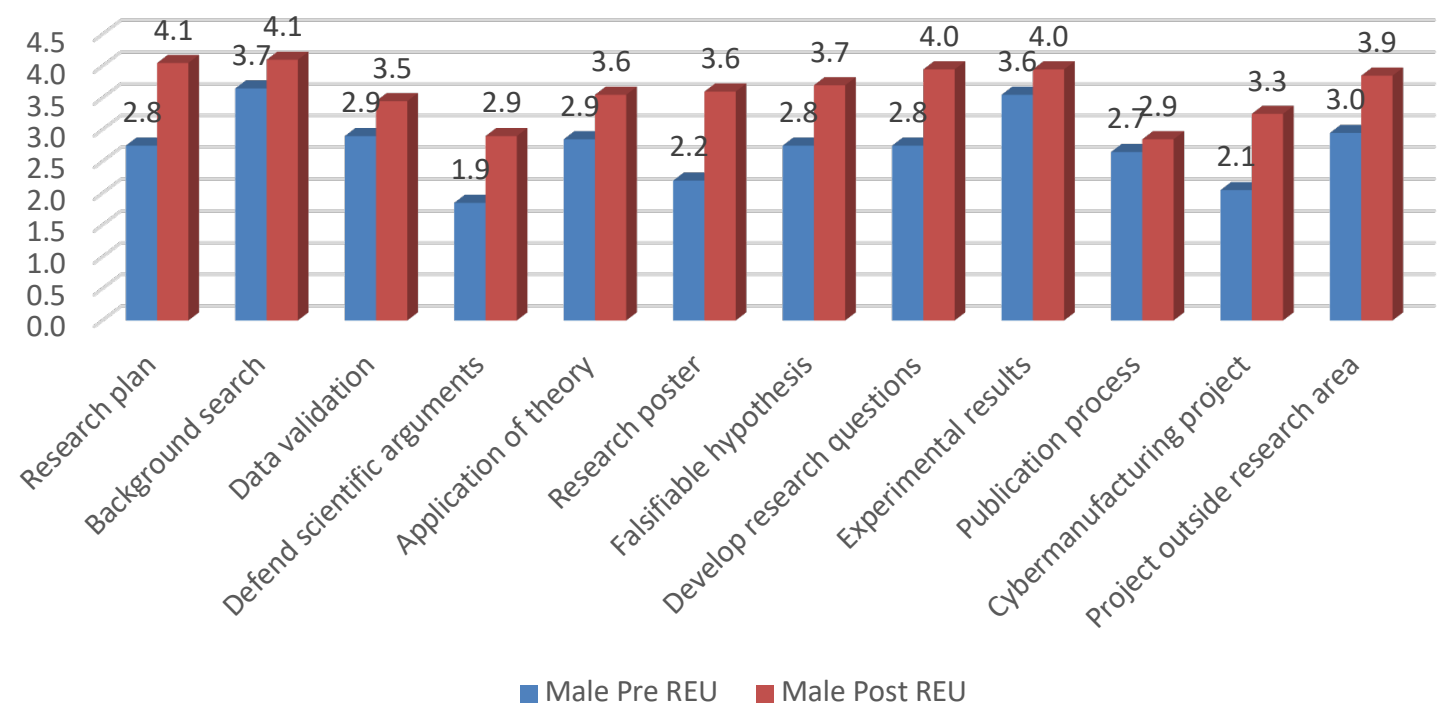

Figure A.3: Average competency score for male participants 


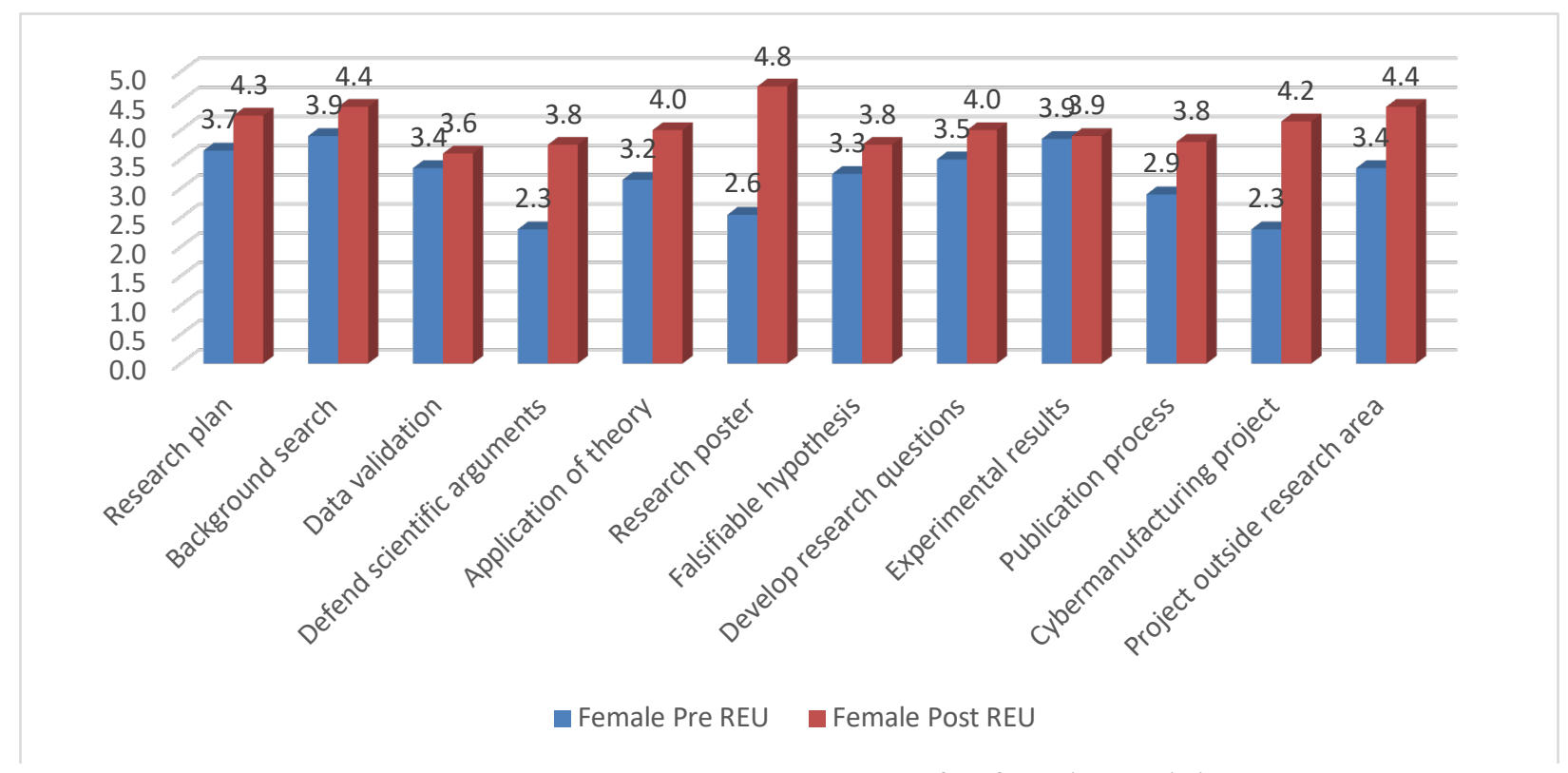

Figure A.4: Average competency score for female participants

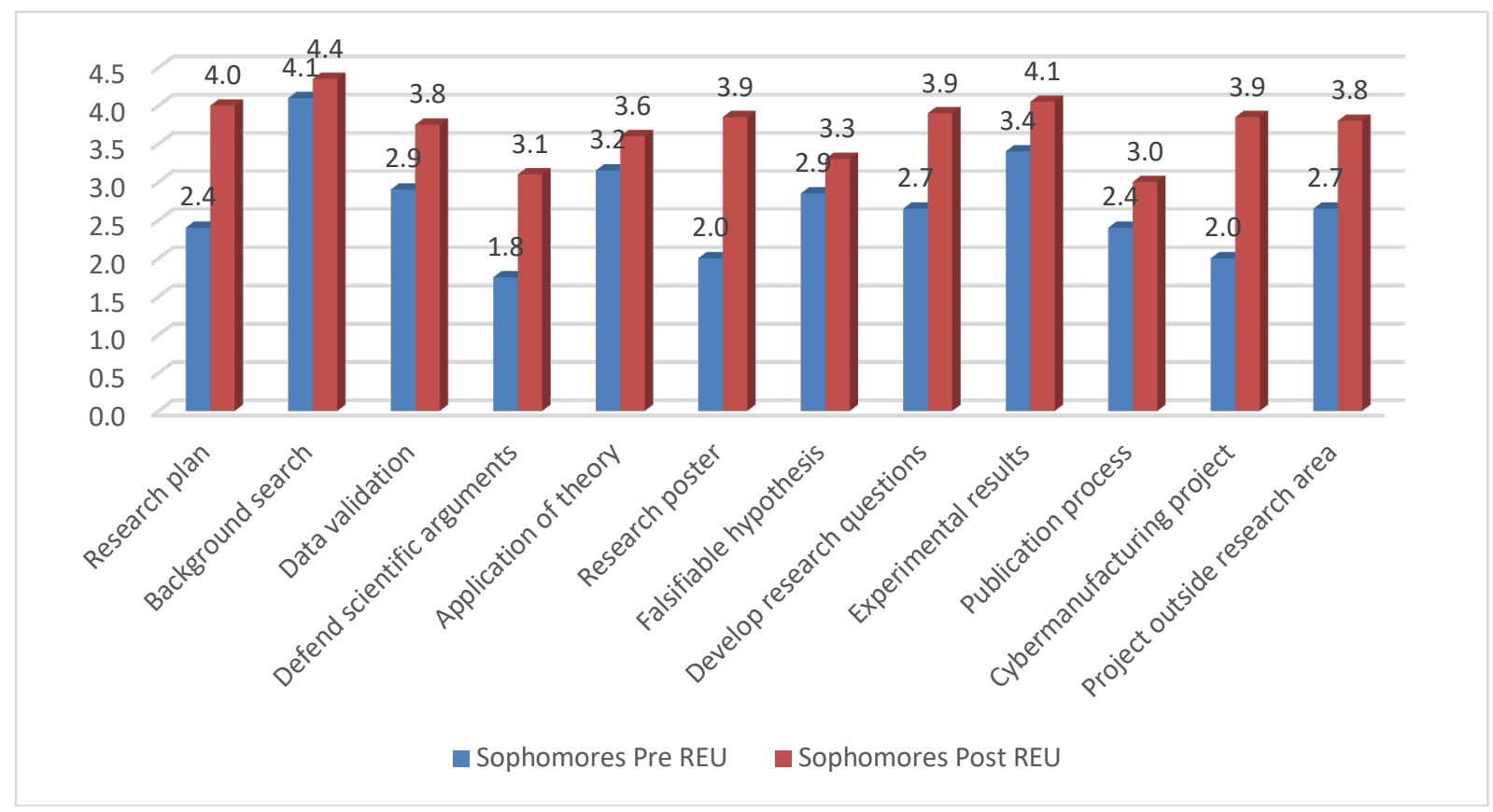

Figure A.5: Average competency score Sophomores 


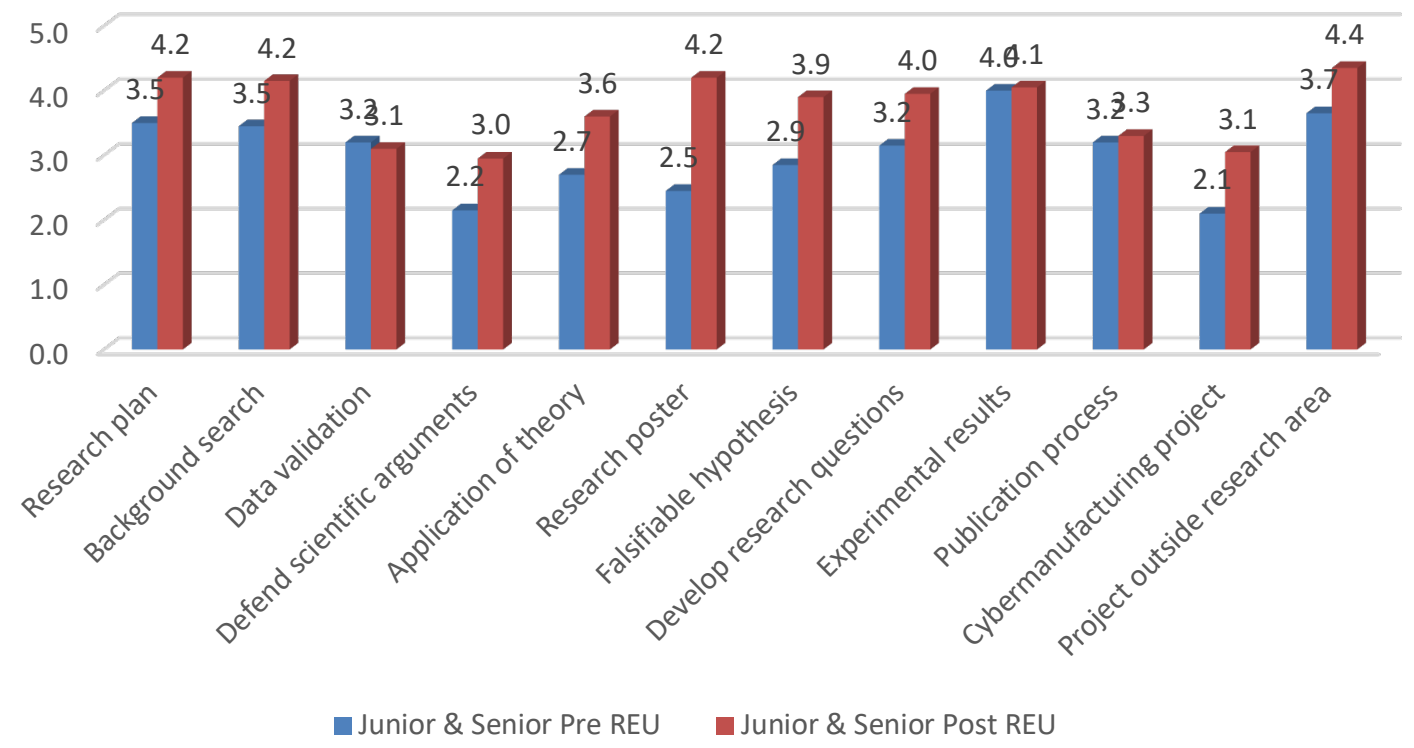

Figure A.6: Average competency score for Juniors \& Seniors

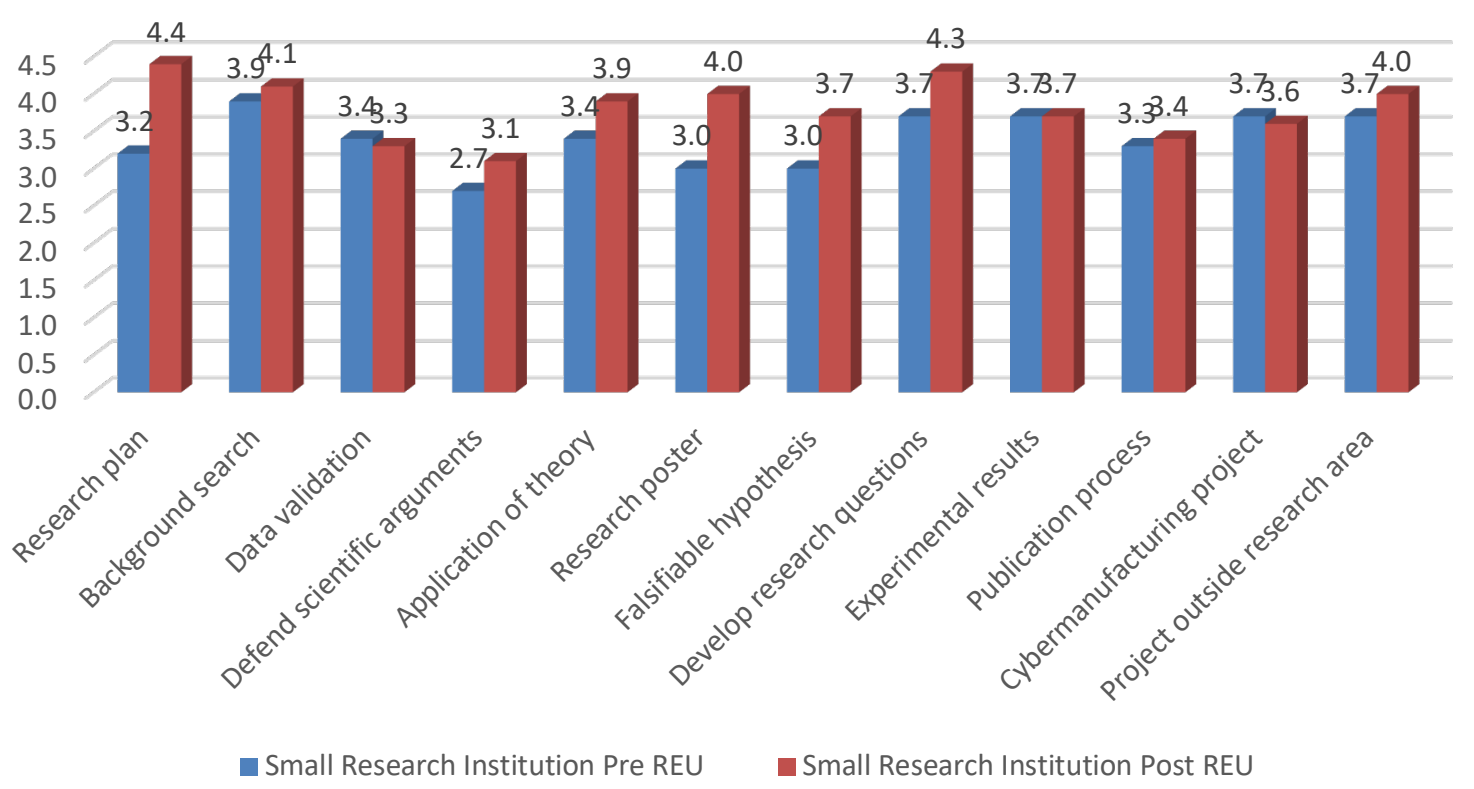

Figure A.7: Average competency score of students from a small research institution 


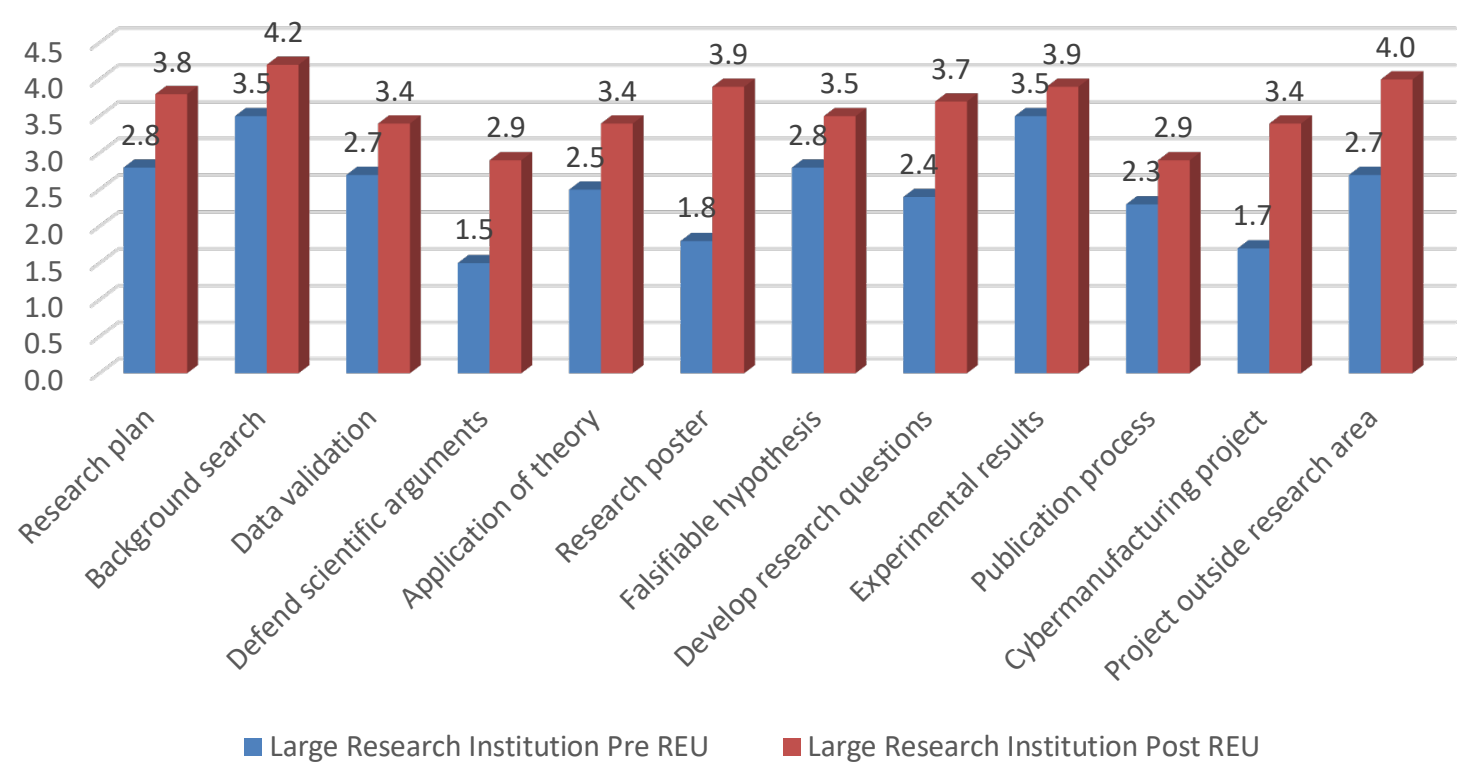

Figure A.8: Average competency score of students from a large research institution 